\title{
Shell morphology changes in the scallop Aequipecten tehuelchus during its life span: a geometric morphometric approach
}

\author{
Federico Márquez ${ }^{1,2,3, *}$, Ricardo Amoroso ${ }^{1,2}$, María Florencia Gowland Sainz ${ }^{2}$ \\ Silvina Van der Molen ${ }^{1}$
}

\author{
${ }^{1}$ Centro Nacional Patagónico CENPAT - CONICET, Blvd. Brown 2915 (U9120ACD), Puerto Madryn, Argentina \\ ${ }^{2}$ Universidad Nacional de la Patagonia San Juan Bosco, Blvd. Brown 3100, Puerto Madryn (U9120ACD), Chubut, Argentina \\ ${ }^{3}$ Universidad Nacional de Córdoba, Av. Vélez Sarsfield 299, Córdoba (X5000JJC), Córdoba, Argentina
}

\begin{abstract}
Shell morphology is a central feature of bivalve biology in fields such as taxonomy, evolution, and functional anatomy. When allometric shell growth occurs, traditional morphometric methods usually fail to provide robust, size-free shape variables. We used a more integrative approach, geometric morphometrics, to examine ontogenetic changes in the shell of the scallop Aequipecten tehuelchus. A single cohort that settled early in 2004 at a site in San José Gulf in northern Patagonia, Argentina, was sampled at irregular intervals over 5 yr. Different developmental stages had significant differences in shell shape. There was significant ontogenetic allometry, mainly reflected in the shape of the shell disc and the symmetry of the auricles. The most noticeable morphological changes in shell shape and size took place within the first $2 \mathrm{yr}$ of life. Three different shell ecophenotypes were discriminated: spat, juveniles, and adults. Spat had a relatively large anterior auricle and a circular disc; auricles in juveniles were more symmetrical and the shell disc more elongated; and during the adult stage the auricles were small and asymmetrical and the disc elliptical. These 3 phenotypes may reflect changes in the scallop's life habits, as individuals develop from attached spat to actively swimming juveniles to more sedentary adults.
\end{abstract}

KEY WORDS: Allometry $\cdot$ Geometric morphometrics $\cdot$ Ontogeny $\cdot$ Shell-shape $\cdot$ Tehuelche scallop

\section{INTRODUCTION}

The shell is generally the most conspicuous part of the mollusk body and, to a large degree, also the most variable in shape. Because intra- and inter-specific variation in shell morphology are the result of the combined effects of genetic differentiation and phenotypic plasticity, its study constitutes a key element in diverse fields such as taxonomy, evolution, functional anatomy, or fisheries management (e.g. Stanley 1970, Gould 1971, Ackerly 1992, Manuel \& Dadswell 1993, Gaspar et al. 2002, Ubukata 2003, Márquez et al. 2010, 2011). Assessment of shell shape variation with traditional methods, i.e. the analysis of linear distances and ratio variables in a standard multivariate framework, has some statistical drawbacks (Sokal \& Rohlf 1995): results are very sensitive to the particular distances and ratios chosen, and these measurements are highly correlated with size (Bookstein 1991, Zelditch et al. 2004), which makes it difficult to obtain robust size-free shape variables. The more recently developed landmarksand semi-landmarks-based method for morphometric analysis, the geometric morphometrics (GM) approach, provides an effective way to avoid confusion between size and shape by preserving shape variables throughout the analysis (Rohlf \& Marcus 1993, Adams et al. 2004, Mitteroecker \& Gunz 2009), which is particularly advantageous when strong allometric growth occurs.

In pectinids, shifts in life habits throughout ontogeny, mainly related to changes in their swimming behavior 
and byssal attachment capacity (Caddy 1972, Gruffydd et al. 1975, Vahl \& Clausen 1980, Tang \& Pantel 2005), are concurrent with allometric changes in shell morphology. Scallops characteristically swim with the hinge hindmost, in a direction perpendicular to the hinge axis, and the right valve lies undermost in the swimming and resting or attached positions (Stanley 1970). Attachment is byssal, with the sagittal plane in a non-vertical position (Yonge 1962). Shifting from a mobile to a more sedentary ecophenotype (or vice versa) occurs in parallel with anatomical modifications of the shell. For example, an elongated anterior auricle is more frequent in attached forms because it is associated with the presence of a byssal sinus (Stanley 1970, 1972). Also, changes in attachment and swimming capacity are related to changes in the shell morphology of the disc margin (Ackerly 1992, Garcia-Esquivel \& Bricelj 1993).

While all scallops have the capacity for free swimming movements for part of their life history, they generally swim more frequently as juveniles (Garcia-Esquivel \& Bricelj 1993), although there is considerable variability among species. Probably all scallops secrete a byssus when young (Verrill 1897), and many species such as Chlamys islandica, C. vitrea, Palliolum furtivum, P. tigerinum, Mimachlamys varia, and M. asperrima (Verrill 1897, Young \& Martin 1989, Arsenault \& Himmelman 1996) retain the ability to form a byssus throughout their lifespan. In general, these species are relatively small or live in areas of strong current flow, and the attachment to rocks or other firmly fixed substrates is obviously advantageous for maintaining their position (Brand 2006). On the other hand, some scallop species cease to form a byssus and live free of attachment on the seabed as juveniles and/or adults. For instance, in Pecten maximus and Placopecten magellanicus, the byssus serves only for temporary attachment and the scallops break free when they grow due to the loss or atrophy of the byssal apparatus (Caddy 1972, Gruffydd et al. 1975). Interestingly, even when adults can release the byssus and swim, scallops byssally attached as adults and those that live free on the bottom show morphological differences in their shells (Stanley 1970).

In north Patagonia, the scallop Aequipecten tehuelchus, which is endemic to the Argentine Biogeographic Province, inhabits shallow shelf bottoms from Rio de Janeiro, Brazil $\left(23^{\circ} \mathrm{S}\right)$, to Camarones, Argentina ( $\left.45^{\circ} \mathrm{S}\right)$. Due to its high commercial value, it is one of the most studied bivalves in north Patagonia, but the shell shape variations during growth have not been fully explored. For example, Ciocco (1992) studied the relationship between shell length and height and auricle symmetry using standard regression techniques, but only in juveniles and adults, not the spat. Moreover, most studies on the Tehuelche scallop were carried out using a mixture of shells from different locations.
The aim of the present study was to characterize and discriminate ontogenetic shell form changes (size + shape) of the scallop Aequipecten tehuelchus by means of geometric morphometric techniques, and to discuss their potential implications for byssal attachment and swimming behavior.

\section{MATERIALS AND METHODS}

Ontogenetic changes in the shell form of Aequipecten tehuelchus were analyzed by applying geometric morphometric techniques to a single cohort sampled over $5 \mathrm{yr}$. The main changes in form were captured by analyzing the variation in the positions of a series of landmarks and semi-landmarks from digital shell images. The presence of an allometric relationship between size and shape was assessed by means of a multivariate regression between an estimator of the size (centroid size) and shape variables (Procrustes coordinates). The shell shape differentiation among age classes was then studied using a canonical variate analysis (CVA) on the residuals from the multivariate regression. The data processing and analysis were performed with the TPSdig2 v 2.16 (Rohlf 2010) and MorphoJ v1.02c (Klingenberg in press).

Study area. San José Gulf (SJG) is a small $\left(817 \mathrm{~km}^{2}\right)$ semi-enclosed bay in northern Patagonia, Argentina (Fig. 1). It is shallow (mean depth $=30 \mathrm{~m}$ ) and elliptical in outline, and connects through a $6.9 \mathrm{~km}$ wide mouth with

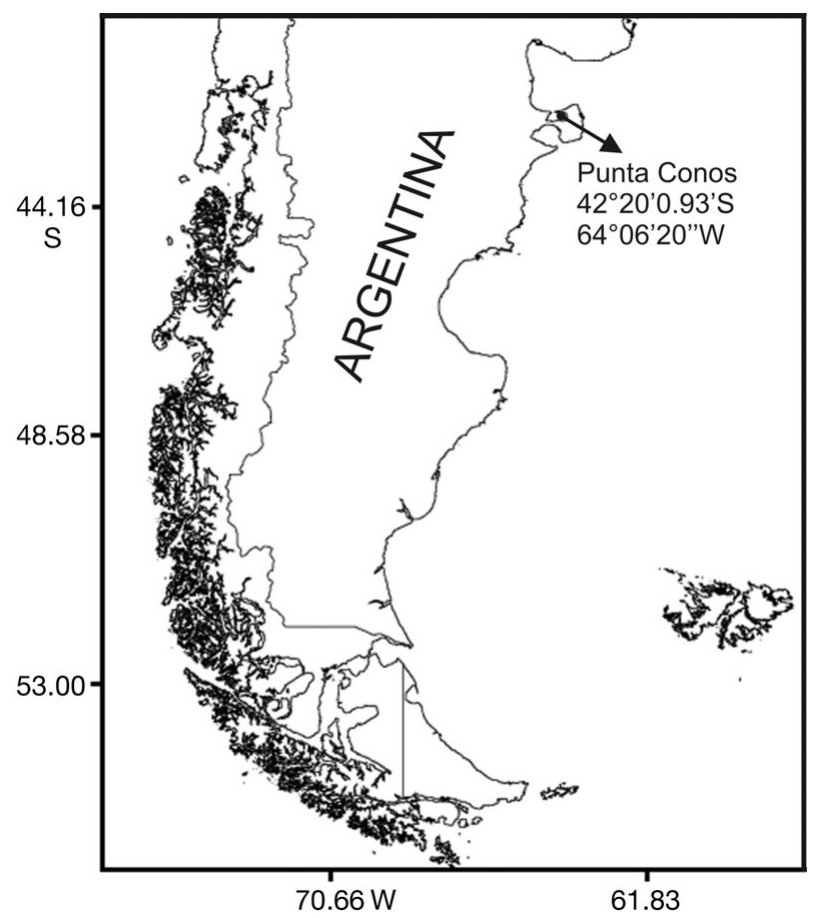

Fig. 1. Sampling location (Punta Conos) inside San José Gulf, Patagonia, Argentina 
the much larger San Matías Gulf $\left(18000 \mathrm{~km}^{2}\right)$. This area is highly productive and supports most of the shellfish catches in the region, the most important species being the Tehuelche scallop Aequipecten tehuelchus. Samples were obtained from an unfished shallow site $(5$ to $10 \mathrm{~m}$ deep) located in the eastern portion of the SJG (Fig. 1, Punta Conos, $42^{\circ} 20^{\prime} 0.93^{\prime \prime} \mathrm{S} ; 64^{\circ} 06^{\prime} 20^{\prime \prime} \mathrm{W}$ ).

Sampling methods. A cohort of Aequipecten tehuelchus that settled early in 2004 was sampled at irregular intervals over 5 yr. The absence of additional newly recruited individuals over the sampling period (Fig. 2) allowed us to assume that all individuals within any sample belonged to the 2004 cohort. The age of individuals was assumed to be the time elapsed between the sampling date and 1 January 2004 (which implies the unrealistic assumption that all individuals were 'born' at the same moment: the first day of the year).

Recently settled recruits are difficult to see on the seafloor, and only after some months can these individuals be sampled by SCUBA divers. For that reason, spat sampling was performed using artificial collectors deployed 1 to $2 \mathrm{~m}$ above the sea bottom. Each collector consisted of $0.4 \times 0.6 \mathrm{~m}$ bags made of $1 \mathrm{~mm}$ mesh, filled with $90 \mathrm{~cm}$ of a plastic polymer (Netlon ${ }^{\circledR}$ ). Before the beginning of the reproductive season (November to February) a set of collectors was placed and replaced monthly. Retrieved collectors were washed with tap water, and the contents sieved over a $1 \mathrm{~mm}$ mesh. Once individuals reached a size that made them visible to the divers, samples were obtained by SCUBA diving using 10 random $1 \mathrm{~m}^{2}$ quadrats.

Data set. For the geometric morphometric analysis, a subset of the individuals sampled on each date was randomly chosen. Shell length (SL) was measured as the straight line between Landmark 1 and 5 (Fig. 3, see below for landmark position details). In total, 454 individuals were sampled: spat $(\mathrm{n}=92$, SL 2.06 to $6.38 \mathrm{~mm}$ ), $0.80 \mathrm{yr}$ old individuals $(\mathrm{n}=58$, SL 27.14 to $40.64 \mathrm{~mm}$ ), $1.09 \mathrm{yr}$ old individuals $(\mathrm{n}=59$, SL 29.88 to $50.00 \mathrm{~mm}$ ), $1.88 \mathrm{yr}$ old individuals $(\mathrm{n}=52$, SL 59.00 to $72.31 \mathrm{~mm}$ ), $2.88 \mathrm{yr}$ old individuals $(\mathrm{n}=41, \mathrm{SL} 73.9$ to $86.34 \mathrm{~mm}$ ), $3.84 \mathrm{yr}$ old individuals $(\mathrm{n}=61$, SL 79.86 to $87.03 \mathrm{~mm}$ ), $4.85 \mathrm{yr}$ old individuals ( $\mathrm{n}=40$, SL 76.5 to $88.12 \mathrm{~mm}$ ), and $5.5 \mathrm{yr}$ old individuals $(\mathrm{n}=51, \mathrm{SL} 78.3$ to $96.36 \mathrm{~mm})$.

After removing the soft parts, right valves were digitized (concave side upwards) with a digital camera. The spat were photographed under a Carl Zeiss binocular magnifying glass equipped with AxioVision Rel.4.5 software (@Carl Zeiss Imaging Solutions).

The Cartesian coordinates of a set of 8 anatomical landmarks and 20 semi-landmarks on each individual shell (Fig. 3) were recorded by 2 observers (F.M. and M.F.G.S.): (1) base of hinge, (2) end of anterior auricle, (3) byssal notch, (4) anterior tip of the shell disc, (5) tan-

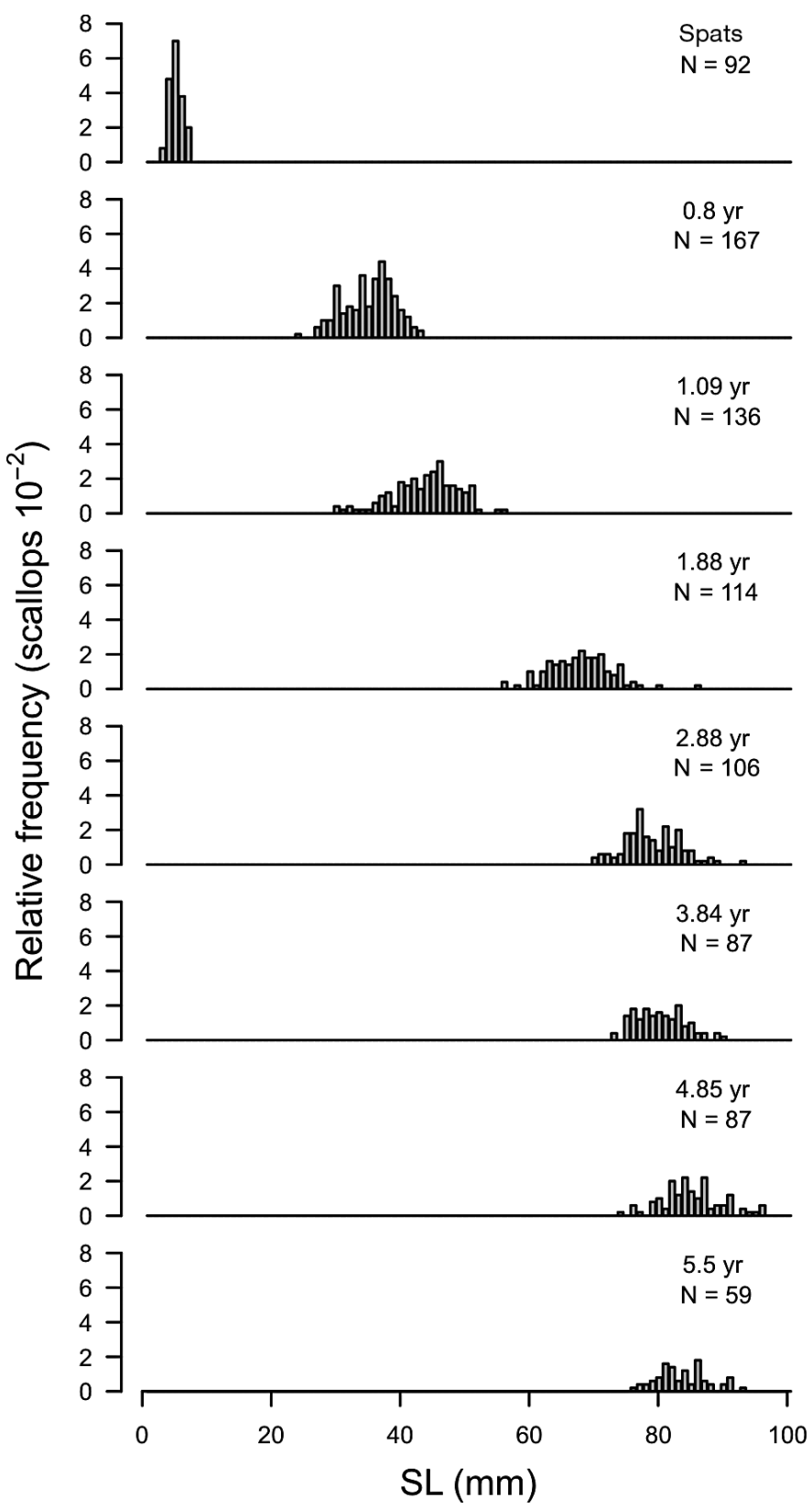

Fig. 2. Aequipecten tehuelchus. Relative size frequency distribution of samples through time. Spat were sampled from artificial collectors. Ages of the 2004 cohort are expressed as time elapsed between the sampling date and 1 January 2004. SL: shell length

gent point in the shell disc, parallel to the plane defined by Landmarks 2 to 8 , (6) posterior tip of the shell disc, (7) inflexion point between the shell disc and posterior auricle, (8) end of the posterior auricle, (9 to 13) semilandmarks along the outline of the posterior auricle, (14 to 18) semi-landmarks along the outline of the anterior auricle, (19 to 23) semi-landmarks along the anterior disc, and (24 to 28 ) semi-landmarks along the posterior disc. 


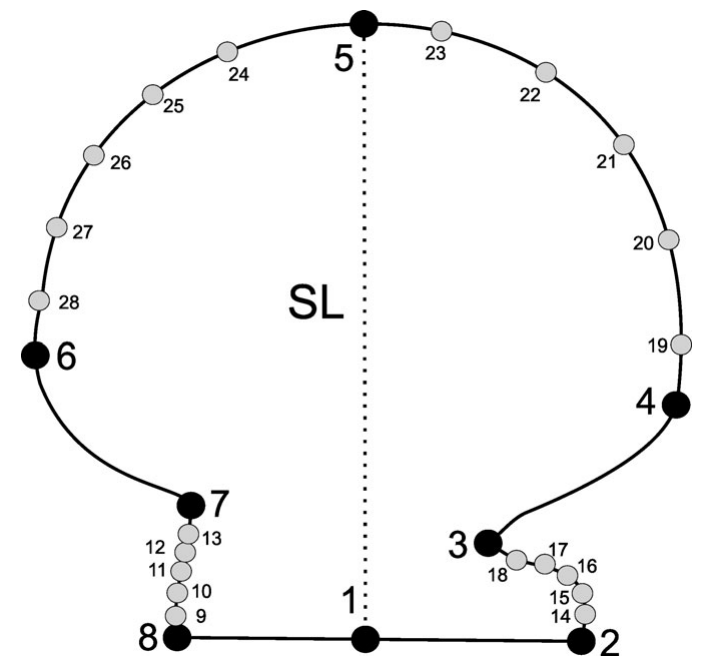

Fig. 3. Aequipecten tehuelchus. Position of the 8 landmarks (black dots) and 20 semi-landmarks (grey dots) on $A$. tehuelchus. SL: shell length (dotted line)

Data processing. Landmark configurations were superimposed by generalized Procrustes analysis (Rohlf \& Slice 1990, Slice et al. 1996). This procedure translates and rotates the landmark configurations to a common origin and scales them to unit centroid size. In subsequent analyses, Procrustes coordinates were used as shape variables. The centroid size was calculated for each specimen as the square root of the sum of the squared deviations of landmarks from the centroid (Zelditch et al. 2004).

Analytical techniques. To distinguish size-related from size-unrelated changes, the presence of allometry was assessed. Here, allometry is used in the sense of Mosimann (1970) as shape changes that are related to increased size. For the analysis of allometry, multivariate regression of shape (Procrustes coordinates used as the dependent variables) on size (centroid size used as the independent variable) was performed (Bookstein 1991, Monteiro 1999). The amount of variation explained by allometry was quantified as the percentage of the total shape variation accounted for by the regression model (Klingenberg \& McIntyre 1998), and the statistical significance of the model was assessed carrying out a permutation test (10000 rounds). The vector of regression coefficients can be visualized as shape changes per unit of size, which allows a direct interpretation in an anatomical context (Drake \& Klingenberg 2008, Klingenberg 2008). To illustrate the form of interdependence, a shape score (the shape variable associated with shape changes predicted by the regression model) is defined by projecting the shape data onto a line in the direction of the regression vector for each independent variable (Drake \& Klingenberg 2008, Klingenberg 2008).
Finally, to find out which size-unrelated shell shape features best discriminated between developmental stages, we performed a CVA of the residuals from the regression of shape on log-transformed centroid size (allometric correction). The use of log-transformed centroid size was suggested by Klingenberg (2008) for ontogenetic studies including very early, small stages where shape change is often concentrated disproportionately. Shape differences along the first canonical variate axis were described using a wireframe graph.

\section{RESULTS}

Allometric growth, in which shape varies with size, was observed. The multivariate regression of shape on centroid size was highly statistically significant (permutation test with 10000 random permutations, p < 0.0001 ), and accounted for $56.20 \%$ of the total amount of shape variation. Shell shape variation of a single cohort, from spat to adults, is shown in Fig. 4. During growth, the main shape changes are related to the mean size increment and are mostly changes in the shell disc, from circular to elliptical, and size and symmetry of the auricles. Shell shape variation over the ontogenetic series suggested 3 average shell shape phases (in Fig. 4 as wireframes): a spat stage (0+ yr) characterized by rapid change of auricle symmetry; a juvenile stage ( 0.8 to $1.88 \mathrm{yr}$ ) where the auricles are symmetrical and the disc circular; and an adult stage ( 2.88 to $5.5 \mathrm{yr}$ ) presenting a more elliptical disc and a slender anterior auricle. The transition between the spat shell shape and juvenile shell shape occurs during age $0+$, while the changes between juveniles and adults are detected after age $2+$. The spat stage had a rapid change in shell shape; changes were then more subtle and formed an asymptote at the end of the juvenile stage until adulthood. The smaller shells have a circular disc and very asymmetrical auricles with a marked byssal notch, the intermediate-sized shells show a more elongated disc and more symmetrical auricles, and the bigger shells present an elongated disc and small, symmetrical auricles.

Different shell shape stages were successfully discriminated using CVA on the residuals from the regression of shape on log-transformed centroid size. The multivariate regression of shell shape on logtransformed centroid size accounted for $64.58 \%$ of the shape variation, and the permutation test indicated that it was statistically significant $(\mathrm{p}<0.0001)$. The first 2 canonical axes (CV) explained $96.35 \%$ of the total variance. The greatest difference in CV1 was between spat and adults; the juvenile stage was intermediate (Fig. 5). The most important shape variation along the CV1 was the difference in the proportions between 


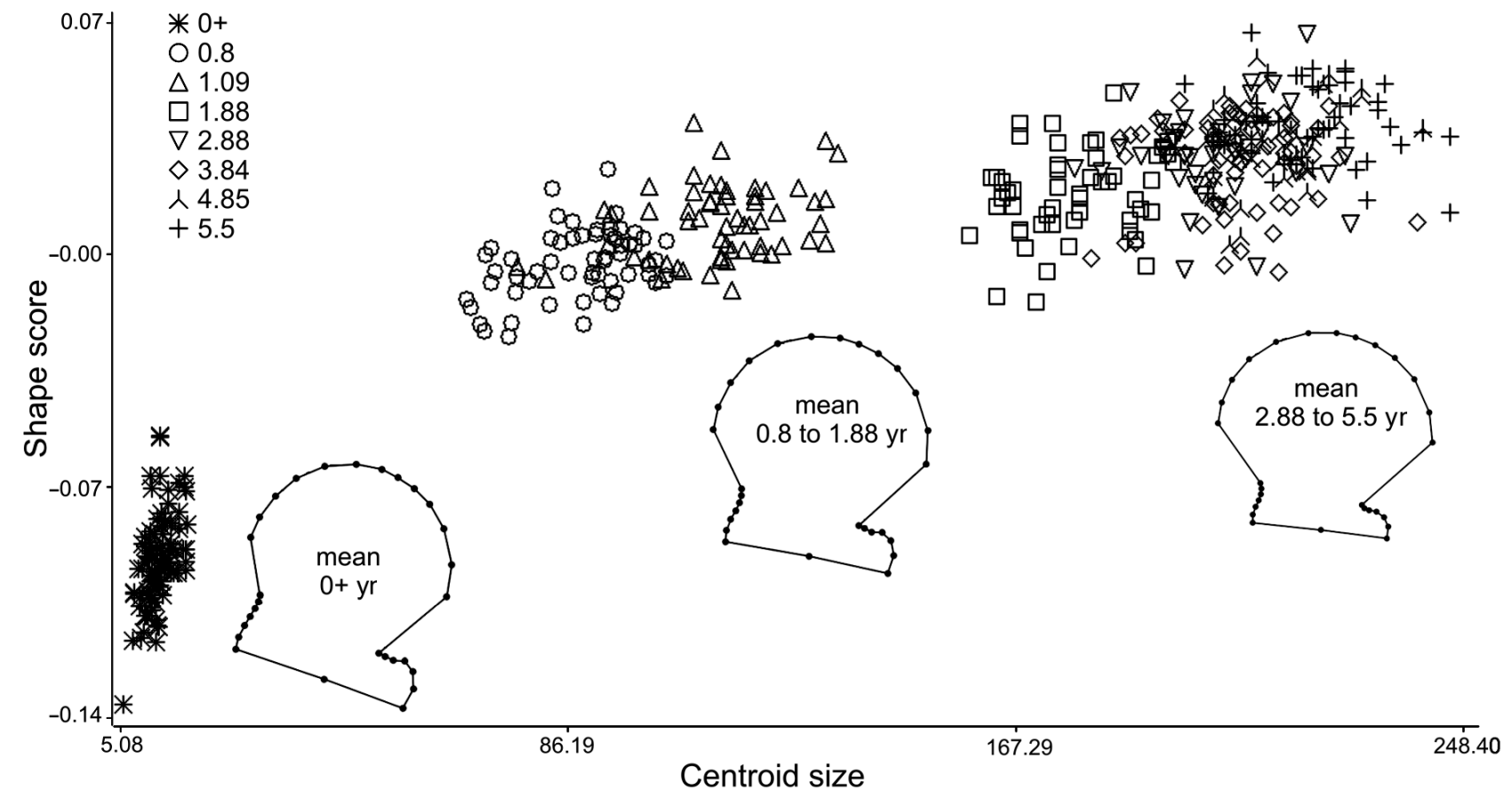

Fig. 4. Aequipecten tehuelchus. Shape scores as a function of centroid size illustrating ontogenetic allometry of A. tehuelchus. Wireframe diagrams show average shell shape at each stage

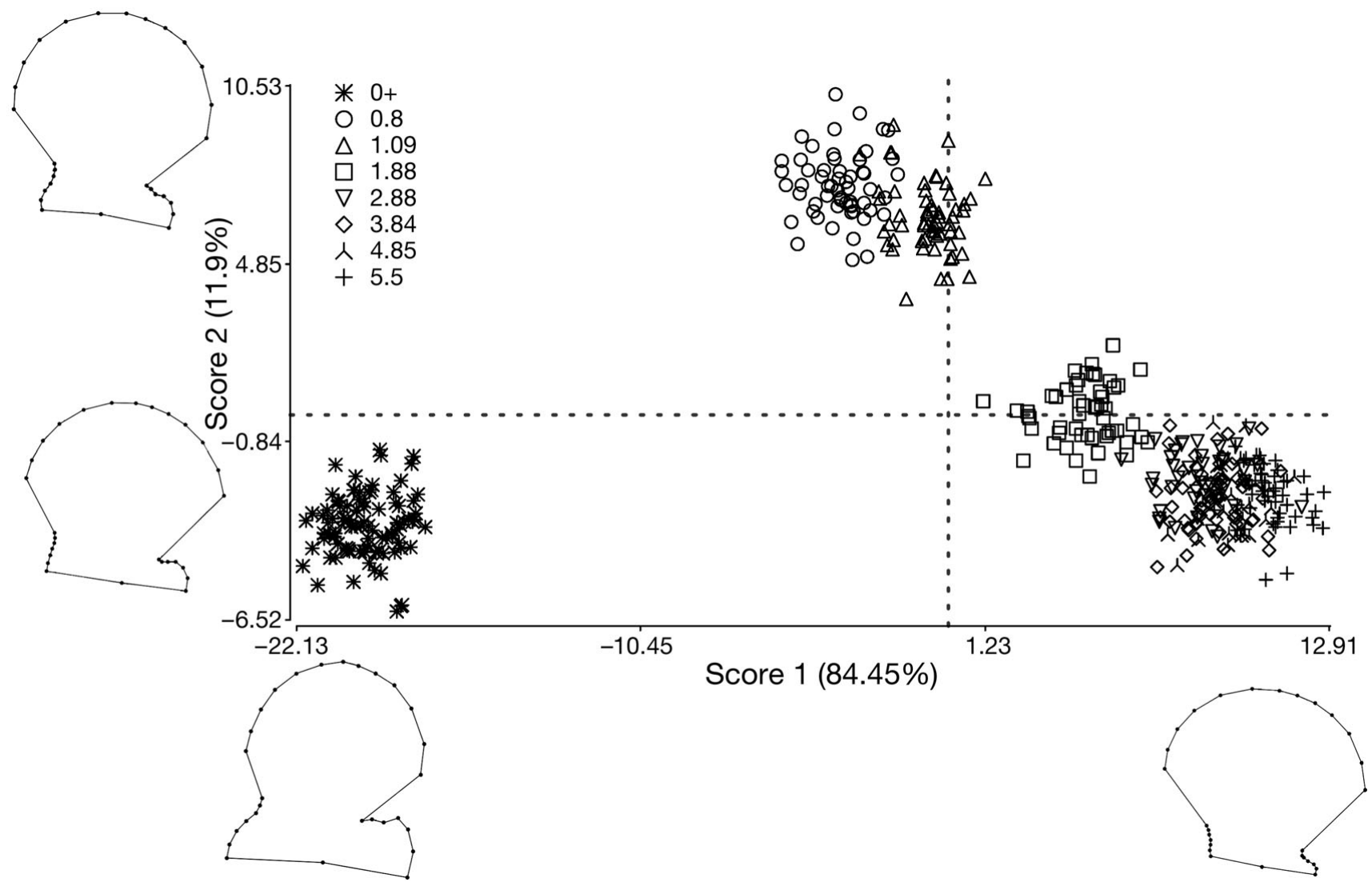

Fig. 5. Aequipecten tehuelchus. Canonical variate analysis of overall shell shape variation along the first 2 canonical axes. Wireframe diagrams show shape changes associated with variation along each axis. The intersection of dotted lines shows the origin of the Cartesian coordinates 
disc and auricles: in the negative scores $(0+$ stage) the disc and auricle dimensions are more balanced than in the positive scores (5.5 yr stage). These differences were produced by the auricle shape variation and the entire shell outline. The major differentiation along CV2 was between the juvenile stage and the other stages; these changes were mostly associated with the symmetry of the auricles and disc circularity.

\section{DISCUSSION}

Aequipecten tehuelchus exhibits important morphological changes throughout ontogeny. Our geometric morphometric analysis suggests that this species has ontogenetic allometry, and the principal shell form changes were related to the size and shape proportions between the auricles and the disc. We characterized 3 phenotypic stages with significantly different morphological patterns. The morphology of the spat stage was related to a bigger anterior auricle and a more circular disc; the juvenile stage presented more symmetrical auricles and an elongated shell disc, and the adult stage mainly showed an elliptical disc and small asymmetrical auricles. These results agree with those of Ciocco (1992), who studied the relationship between shell length and height of juveniles and adults based solely on their dimensions. However, in our study, the use of geometric morphometric techniques allowed us to detect subtle changes in the shape of the disc and auricles.

An elongated anterior auricle is a very important functional feature of many non-vertical, byssally attached species. The marked trend towards high auricle asymmetry and the relative elongation of the anterior auricle are explained by their role as a support to prevent overturning of the shell (Stanley 1970). Pectinids show a wide range of life habits, from free swimming to fixed forms, related to the changing attachment capacity throughout ontogeny (see Caddy 1972, Gruffydd et al. 1975, Vahl \& Clausen 1980, Tang \& Pantel 2005). In Aequipecten tehuelchus, byssal attachment gradually disappears with age, but the capacity to form a byssus is not lost in adults (Ciocco et al. 1983). Even when both are more or less fixed to the substrate, $A$. tehuelchus spat and adults have different physical requirements for attachment: for example, adults occupy a wider range of habitats than spat (Ciocco et al. 2006). Our results suggest that this feature is reflected in the shape of the disc, the auricle asymmetry, and the proportions of the disc and auricles.

In Aequipecten tehuelchus, as in other scallop species, swimming involves clapping of the valves (Ciocco et al. 1983). Sharp contractions of the adductor muscle force jets of water out of the mantle cavity, propelling the scallop in the direction opposite to the jet. Swimming ability declines, and may disappear, during the ontogeny of scallops that swim well as juveniles (Gould 1971). For example, in a study on dispersal and migration via tagging experiments, Melvin et al. (1985) determined that mid-sized Placopecten magellanicus (SL 60 to $89 \mathrm{~mm}$ ) traveled greater distances than smaller or larger individuals. Garcia-Esquivel \& Bricelj (1993) also determined that mid-sized juvenile bay scallops Argopecten irradians irradians swim more than smaller juveniles and adults. They suggested that the greater swimming rates of intermediate sized juveniles may represent a behavioral response to predation, following the period when smaller juveniles exploit a spatial refuge from predation by attaching to the eelgrass canopy and before the period when they reach a size refuge from predation. Due to its shell shape, the juvenile stage in $A$. tehuelchus may represent the stage with the highest motility. Juvenile $A$. tehuelchus have symmetrical auricles and a circular to elliptical shell disc, and the relationship between these features may decrease frictional drag and increase the lift coefficient, providing an advantage in swimming (for a description of these forces, see Gould 1971). The relationship between shell morphology and swimming capacity was also described for $P$. magellanicus (Dadswell \& Weihs 1990), and several Pecten species (Ackerly 1992). Stanley (1970) noted that swimming is enhanced by broad shell outlines with large umbonal angles, a shape which permits the dorsally directed jets necessary for swimming.

Scallop beds frequently show a regional separation of year-classes that is probably largely a consequence of spatial differences in time of settlement and early survival (Brand 2006). The possibility of scallops settling in nursery areas, where conditions are particularly favorable for settlement and early survival, and dispersing later onto adult beds has often been suggested but until recently there was little evidence for any species (Brand 2006). In the case of Aequipecten tehuelchus from the SJG, spat settlement occurs primarily on the macroalga Ulva sp. (Ciocco et al. 2006), and adults are mainly fixed to the sediment, shells of dead scallops, and empty shells of other bivalves (Ciocco et al. 1983). The habitat shift from the spat micro-environment to adult beds by the dispersion of juveniles may be reflected in the different shell shapes we distinguished.

This is the first time that ontogenetic allometry has been studied in a wild cohort of Aequipecten tehuelchus. We found a significant association between shell shape and shell size during ontogeny. These shell morphology changes may reflect the behavioral and habitat changes from attached spat to active swimming juveniles and then to more sedentary adults. 
Acknowledgements. We thank M. A. Diaz, J. Rúa, R. Vera, N. Ortiz, C. Fernández, F. Quiroga, and A. Márquez Idaszkin for their help in the field and the laboratory. We also thank the Administración de Parques Nacionales and the Administración Area Natural Protegida Península Valdés for their cooperation. The manuscript was greatly improved by the comments and constructive criticisms of 3 anonymous reviewers. Institutional support was provided by Centro Nacional Patagónico (CONICET).

\section{LITERATURE CITED}

Ackerly S (1992) The structure of ontogenetic variation in the shell of Pecten. Palaeontology 34:847-867

Adams DC, Rohlf FJ, Slice D (2004) Geometric morphometrics: ten years of progress following the 'revolution'. Ital J Zool 71:5-16

Arsenault DJ, Himmelman JH (1996) Ontogenic habitat shifts of the Iceland scallop, Chlamys islandica (Müller, 1776), in the northern Gulf of St Lawrence. Can J Fish Aquat Sci 53:884-895

Bookstein FL (1991) Morphometric tools for landmark data. Cambridge University Press, New York, NY

Brand AR (2006) Scallop ecology: distributions and behavior. In: Shumway SE, Parsons GJ (eds) Scallops: biology, ecology and aquaculture. Elsevier, New York, NY, p 651-744

Caddy JF (1972) Progressive loss of byssus attachment with size in the sea scallop Placopecten magellanicus (Gmelin.). J Exp Mar Biol Ecol 9:179-190

Ciocco NF (1992) Anatomía de la vieira Tehuelche Chlamys tehuelcha (d'Orb.). I. Valvas, ligamento y manto (Pelecypoda, Pectinidae). Neotrópica (La Plata) 38:21-34

Ciocco NF, Borzone CA, Ruzzante DE (1983) Observaciones sobre el comportamiento de fijación de Chlamys tehuelchus d'Orbigny en bancos naturales. Mem Asoc Latinoam Acuic 5:271-275

Ciocco NF, Lasta ML, Narvarte M, Bremen C, Bogazzi E, Valero J, Orenzans JM (2006) Argentina. In: Shumway SE, Parsons GJ (eds) Scallops: biology, ecology and aquaculture. Elsevier, New York, NY, p 1251-1292

Dadswell MJ, Weihs D (1990) Size-related hydrodynamic characteristics of the giant scallop Placopecten magellanicus (Bivalvia: Pectinidae). Can J Zool 68:778-785

Drake AG, Klingenberg CP (2008) The pace of morphological change: historical transformation of skull shape in St. Bernard dogs. Proc Biol Sci 275:71-76

Garcia-Esquivel Z, Bricelj VM (1993) Ontogenetic changes in microhabitat distribution of juvenile bay scallops, Argopecten irradians irradians (L.), in eelgrass beds, and their potential significance to early recruitment. Biol Bull (Woods Hole) 185:42-55

Gaspar MB, Santos MN, Vasconcelos P, Monteiro CC (2002) Shell morphometric relationships of the most common bivalve species (Mollusca: Bivalvia) of the Algarve coast (southern Portugal). Hydrobiologia 477:73-80

Gould SJ (1971) Muscular mechanics and the ontogeny of swimming in scallops. Palaeontology 14:61-94

Gruffydd LD, Lane DJ, Beaumont AR (1975) The glands of the larval foot in Pecten maximus L. and possible homologues in other bivalves. J Mar Biol Assoc UK 5:463-473

Klingenberg CP (2008) MorphoJ. Faculty of Life Sciences, University of Manchester. www.flywings.org.uk/MorphoJ_ guide/frameset.htm?index.htm

Klingenberg CP (in press) MorphoJ: an integrated software package for geometric morphometrics. Mol Ecol Resour doi: 10.1111/j.1755-0998.2010.02924.x

Klingenberg CP, McIntyre GS (1998) Geometric morphomet-

Editorial responsibility: Judith Grassle,

New Brunswick, New Jersey, USA rics of developmental instability: analyzing patterns of fluctuating asymmetry with Procrustes methods. Evolution 5:1363-1375

> Manuel JL, Dadswell MJ (1993) Swimming of juvenile sea scallops, Placopecten magellanicus (Gmelin): a minimum size for effective swimming? J Exp Mar Biol Ecol 174: $137-175$

Márquez F, Robledo J, Escati Peñalosa G, Van Der Molen S (2010) Use of different geometric morphometrics tools for the discrimination of phenotypic stocks of the striped clam Ameghinomya antiqua (Veneridae) in San José Gulf, Patagonia, Argentina. Fish Res 101:127-131

Márquez F, González-José R, Bigatti G (2011) Combined methods to detect pollution effects on shell shape and structure in neogastropods. Ecol Indic 11:248-254 (in press) doi:10.1016/j.ecolind.2010.05.001

Melvin GD, Dadswell MJ, Chandler RA (1985) Movement of scallops Placopecten magellanicus (Gmelin, 1971) (Mollusca: Pectinidae) on Georges Bank. Can Atl Fish Sci Adv Comm Res Doc 85/30

Mitteroecker P, Gunz P (2009) Advances in geometric morphometrics. Evol Biol 36:235-247

Monteiro LR (1999) Multivariate regression models and geometric morphometrics: the search for causal factors in the analysis of shape. Syst Biol 48:192-199

> Mosimann JE (1970) Size allometry: size and shape variables with characterization of the lognormal and generalized gamma distributions. J Am Stat Assoc 65:930-945

Rohlf FJ (2010). TPSDig2 version 2.16. Department of Ecology and Evolution, State University of New York at Stony Brook, NY

> Rohlf FJ, Marcus LF (1993) A revolution in morphometrics. Trends Ecol Evol 8:129-132

Rohlf FJ, Slice D (1990) Extensions of the Procrustes method for the optimal superimposition of landmarks. Syst Zool 39:40-59

Slice DE, Bookstein FL, Marcus LE, Rohlf FJ (1996) Appendix I: a glossary for geometric morphometrics. In: Marcus LE, Corti M, Loy A, Naylor GJP, Slice D (eds) Advances in morphometrics. Plenum Press, New York, NY, p 531-551

Sokal RR, Rohlf FJ (1995) Biometry. Freeman \& Co, New York, NY

Stanley SM (1970) Relation of shell form to life habitats in the Bivalvia (Mollusca). Mem Geol Soc Am 125:1-296

Stanley SM (1972) Functional morphology and evolution of byssally attached bivalve mollusks. J Paleontol 46:165-212

Tang C, Pantel JH (2005) Combining morphometric and paleoecological analyses: examining small-scale dynamics in species-level and community-level evolution. Palaeontol Electron 8:33A http://palaeoelectronica.org/paleo/2005_2/ combine/issue2_05.htm

> Ubukata T (2003) A morphometric study on morphological plasticity of shell form in crevice-dwelling Pterioida (Bivalvia). Biol J Linn Soc 79:285-297

Vahl O, Clausen B (1980) Frequency of swimming and energy cost of byssus production in Chlamys islandica (O.F. Müller). J Cons Int Explor Mer 39:101-103

Verrill AE (1897) A study of the family Pectinidae, with a revision of the genera and subgenera. Trans Conn Acad Arts Sci 10:41-96

Yonge CM (1962) On the primitive significance of the byssus in the Bivalvia and its effects in evolution. J Mar Biol Assoc UK 42:113-125

Young PC, Martin RB (1989) The scallop fisheries of Australia and their management. Rev Aquat Sci 1:615-638

Zelditch ML, Swiderski DL, Sheets HD, Fink WL (2004) Geometric morphometrics for biologists: a primer. Elsevier, New York, NY

Submitted: April 8, 2010; Accepted: October 13, 2010

Proofs received from author(s): December 6, 2010 